Thorax, 1979, 34, 563-564

\title{
Chondritis associated with fatal intramural bronchial fibrosis
}

\section{TIM HIGENBOTTAM AND JANE DIXON}

From the Brook General Hospital and Department of Morbid Anatomy, University College Hospital, London, UK

In a case of progressive and ultimately fatal stenosis of the main bronchi due to intramural bronchial fibrosis associated with degeneration of the bronchial cartilage plates there were pathological similarities to relapsing polychondritis, but unlike previously reported cases the disease was confined to the major bronchi.

\section{Case report}

A 46-year-old woman presented with a six-month history of an unproductive cough and wheezy breathlessness. There was no previous history of respiratory disease, and she described no symptoms related to her ears, eyes, nose, or throat. For 18 months before the onset of breathlessness she had received propranolol, $40 \mathrm{mg}$ thrice daily, for hypertension (BP 160/110 $\mathrm{mmHg}$ ); this, however, had been stopped on the onset of breathlessness. Clinically, the breath sounds over the anterior of the left side of her chest were reduced and were out of phase with those heard at her mouth.

Respiratory function tests confirmed a severe obstructive ventilatory defect with a normal gas transfer factor for carbon monoxide. Her ESR was $1 \mathrm{~mm} /$ hour, white cell count $9.8 \times 10^{\circ} / 1,14.6 \mathrm{~g} / \mathrm{dl}$. Rheumatoid and antinuclear factors were negative, but there were strongly positive antibodies to gastric parietal cells.

The plain chest radiograph was clear, but tomography showed a stenosed left main bronchus for a length of $2 \mathrm{~cm}$. Computerised axial tomography showed no mediastinal cause for the bronchial narrowing but did show that both right and left main bronchi were stenosed.

Bronchoscopy performed under general anaesthetic confirmed that both right and left main bronchi were concentrically narrowed, the left more so than the right. A biopsy of the left main bronchial mucosa showed no evidence of amyloid, granuloma, or tumour.

An initial four-week course of prednisolone, $30 \mathrm{mg}$ daily, failed to produce any improvement and was followed by dexamethasone, $16 \mathrm{mg}$, and cyclophosphamide, $200 \mathrm{mg}$ daily. Despite this, her clinical state deteriorated over the next four weeks and as a final attempt to relieve the severe left main bronchial stenosis she received for four days $150 \mathrm{rads}$ a day of radiotherapy to the left hilum. She died during this course of treatment, three months after first attending outpatients.

\section{Necropsy}

At necropsy there were no abnormalities of nose, eyes, ears, or joints. Both main bronchi were narrowed throughout their length, the left more severely than the right, with associated diffuse thickening of the bronchial wall to a maximum of $0.4 \mathrm{~cm}$. There was a similar thickening of the walls of their major branches up to and including the segmental bronchi.

Multiple sections through the main bronchi and major branches showed widespread cartilagenous degeneration with replacement by dense fibrous tissue. Almost normal cartilage plates were found next to areas of almost complete fibrous replacement. The disintegration appeared to start at the periphery of the plate (fig 1) with focal ingrowths of perichondrium. In more severe stages shrunken chondrocytes were

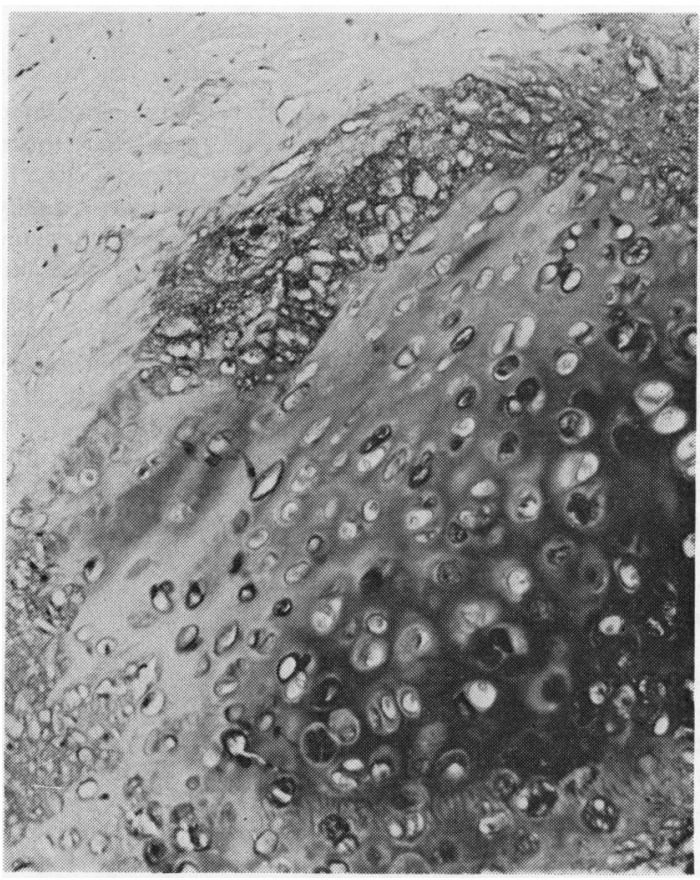

Fig 1 Bronchial cartilage plate showing peripheral disintegration and surrounding fibrosis with virtual absence of inflammatory cells (Haematoxylin and eosin $\times 124$ ). 
present in residual matrix, from which star-like processes of myxoid connective tissue extended to blend intimately with surrounding collagenous connective tissue (fig 2). There was a conspicuous lack of inflammatory cells in any of the sections.

Remnants of cartilage had a variable staining reaction, being partially basophilic and partially eosinophilic, the proportion being no greater than in control bronchial cartilage from a woman of similar age.

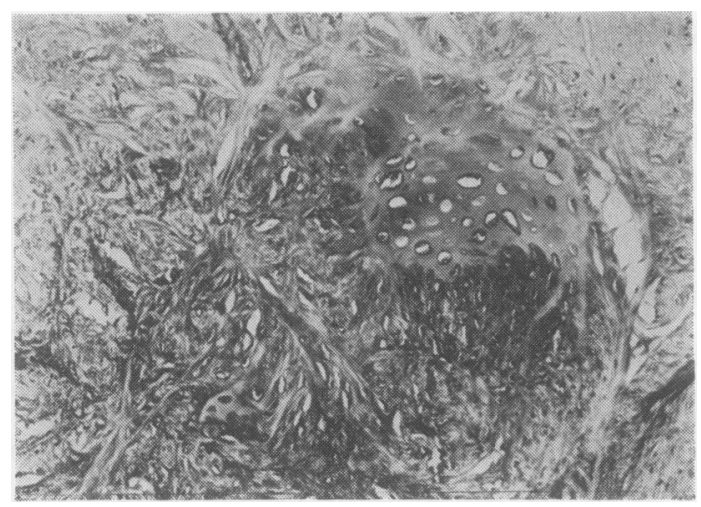

Fig 2 Partially destroyed bronchial cartilage plate with fibrous replacement ( $H$ and $E \times 99$ ).

\section{Discussion}

Extensive intramural bronchial fibrosis associated with cartilagenous degeneration has previously been described only in relapsing polychondritis (Purcelli et al, 1962; Kaye et al, 1964). Such patients normally present with symptoms of inflammation of cartilage of the joints, ears, and nose. Respiratory involvement occurs later, often confined to the cartilage of the larynx and trachea (McAdam et al, 1976). The histological appearance is one of a vigorous inflammatory response in which the basophilic matrix of the affected cartilage is replaced by more eosinophilic material and fibrous tissue. Our histological findings could represent a late stage in the disease (Purcelli et al, 1962). Indeed, our patient had been troubled for nine months, and had taken corticosteroids for three months, which may have altered the inflammatory reaction.

A combination of steroids and an immunosuppressant agent, such as azathioprine or cyclophosphamide, is usually successful in curtailing relapses of chondritis. However, involvement of the intrathoracic trachea or main bronchi, as in our patient, may despite treatment prove fatal (McAdam et al, 1976).
The cause of chondritis remains obscure. Irn? relapsing polychondritis the onset in middle life름 absence of family history, and patchy nature of thes cartilage disease suggests an acquired disordero (McAdam et al, 1976) and there is also often an associated immunological involvement. Many of thes reported cases have associated immune diseases such $\vec{b}$ as rheumatoid arthritis, some show histologicaL similarities to polyarteritis nodosa, and specific anti $\vec{\omega}$ bodies to type II collagen have been reported during? the active phases of the disease (Foidart et al, 1978) Our patient showed no evidence of immunological involvement except for the gastric parietal celf antibodies.

A delayed granulomatous bronchial chondritis has been described after the inhalation of ethyleneimine (Gresham and West, 1975). Our patient, however, gave no history of exposure to such agents and no previous acute respiratory illness. It is of interest, however that she had been taking propranolol for 18 month before the onset of symptoms. Whether this isp. coincidental we cannot tell, but it is worth noting that practolol, a similar "beta-blocker" has beert incriminated as a cause not only of pleural ande pulmonary fibrosis but also of small airway stenosi (Marshall et al, 1977).

We wish to thank Dr Wraith, Professor J F Smithơ and Dr P Forgacs.

\section{References}

Foidart, J, Abe, S, Martin, G R, Zizic, T M, Barnett? E V, Lawley, T J, and Katz, S I (1978). Antibodies to type II collagen in relapsing polychondritis. New England Journal of Medicine, 299, 1203-1207.

Gresham, G A, and West, I E (1975). Injury and re pair of tracheobronchial cartilage following acciv dental exposure to ethyleneimine. Journal of 0 Clinical Pathology, 28, 564-567.

Kaye, R L, and Sones, D A (1964). Relapsing polye chondritis. Annals of Internal Medicine, 60, 653 일

Marshall, A J, Eltringham, W K, Barritt, D Wo Davies, J D, Griffiths, D A, Jackson, L K, Laszo $G$, and Read, A E (1977). Respiratory disease associated with practolol therapy. Lancet, 2, 1254․․․ 1256.

McAdam, L P, O'Hanlan, M A, Bluestone, R, anđ Pearson, C 'M (1976). Relapsing polychondritis Medicine, 55, 193-215.

Purcelli, F M, Nahum, A, and Monell, C (1962) Relapsing polychondritis with tracheal collapse Annals of Otology, Rhinology and Laryngologyo 21, 1120-1129.

Requests for reprints to: Dr Tim Higenbottam. Guy's Hospital, London SE1 9RT. 